\title{
Clinical utility gene card for: inherited optic neuropathies including next-generation sequencing-based approaches
}

\author{
Neringa Jurkute ${ }^{1} \cdot$ Anna Majander $^{2} \cdot$ Richard Bowman $^{3} \cdot$ Marcela Votruba $^{4} \cdot$ Stephen Abbs $^{5} \cdot$ James Acheson $^{6}$. \\ Guy Lenaers ${ }^{7} \cdot$ Patrizia Amati-Bonneau ${ }^{7,8} \cdot$ Mariya Moosajee $^{3,6,9} \cdot$ Gavin Arno $^{6,9} \cdot$ Patrick Yu-Wai-Man ${ }^{1,10,11,12}$
}

Received: 14 December 2017 / Revised: 14 June 2018 / Accepted: 17 July 2018 / Published online: 24 August 2018

(c) European Society of Human Genetics 2018

\section{Disease characteristics}

\subsection{Name of the disease (synonyms)}

Inherited optic neuropathies can be caused by mitochondrial DNA (mtDNA) variants as in Leber hereditary optic neuropathy (Table 1) or by variants in nuclear-encoded genes (Table 2).

\subsection{OMIM\# of the Disease}

Please refer to Tables 1 and 2 .

\subsection{Name of the analysed genes or DNA/ chromosome segments}

\subsubsection{Core genes (irrespective of being tested by Sanger sequencing or next-generation sequencing)}

Core disease-causing genes have been listed in Tables 1 and 2 and marked with ${ }^{\mathrm{b}}$ symbol.

Patrick Yu-Wai-Man

py237@cam.ac.uk

1 NIHR Biomedical Research Centre at Moorfields Eye Hospital and UCL Institute of Ophthalmology, London, UK

2 Department of Ophthalmology, Helsinki University Hospital, University of Helsinki, Helsinki, Finland

3 Department of Ophthalmology, Great Ormond Street Hospital for Children NHS Foundation Trust, London, UK

4 School of Optometry and Vision Sciences, Cardiff University, and Cardiff Eye Unit, University Hospital Wales, Cardiff, UK

5 Department of Clinical Genetics, Cambridge University Hospitals NHS Foundation Trust, Cambridge, UK

6 Moorfields Eye Hospital NHS Foundation Trust, London, UK
1.3.2 Additional genes (if tested by next-generation sequencing, including whole-exome/genome sequencing and panel sequencing)

Additional disease-causing genes have been listed in Tables 1 and 2.

\subsection{Mutational spectrum}

Inherited optic neuropathies are a clinically heterogeneous group of disorders that can be caused by variants in both the nuclear and mitochondrial genomes. MtDNA variants (Table 1) show strict maternal inheritance whereas nuclear variants can be inherited in dominant, recessive or X-linked patterns of inheritance (Table 2). Rarely, de novo variants have also been reported.

The two most common inherited optic neuropathies are autosomal dominant optic atrophy (DOA) secondary to variants in the OPAl gene (OMIM 165,500) and LHON (OMIM 535,000). LHON is caused by mtDNA variants and three so-called primary variants, $m .3460 G>A$, $m .11778 G>A$, and $m .14484 T>C$, account for $\sim 90 \%$ of

7 PREMMi/Mitochondrial Medicine Research Centre, Institut MITOVASC, CNRS UMR 6015, INSERM U1083, Université d'Angers, CHU d'Angers, Angers, France

8 Department of Biochemistry and Genetics, UMR CNRS 6015INSERM U1083, CHU Angers, Angers, France

9 Institute of Ophthalmology, University College London, London, UK

10 Newcastle Eye Centre, Royal Victoria Infirmary, Newcastle upon Tyne, UK

11 Cambridge Eye Unit, Addenbrooke's Hospital, Cambridge University Hospitals, Cambridge, UK

12 Cambridge Centre for Brain Repair and MRC Mitochondrial Biology Unit, Department of Clinical Neurosciences, University of Cambridge, Cambridge, UK 
Table 1 Mitochondrial DNA (mtDNA) variants identified in patients with LHON

\begin{tabular}{|c|c|c|c|c|}
\hline $\begin{array}{l}\text { Name of the } \\
\text { disease }\end{array}$ & $\begin{array}{l}\text { OMIM\# } \\
\text { of the } \\
\text { disease }\end{array}$ & Variant & $\begin{array}{l}\text { Associated } \\
\text { gene(s) }\end{array}$ & $\begin{array}{l}\text { OMIM\# of } \\
\text { associated } \\
\text { gene(s) }\end{array}$ \\
\hline \multirow[t]{10}{*}{$\begin{array}{l}\text { Leber hereditary } \\
\text { optic neuropathy } \\
\text { (LHON) }\end{array}$} & \multirow[t]{10}{*}{535,000} & $\begin{array}{l}\text { m.11778G }>A^{\mathrm{a}} \\
m .11696 G>A \\
m .11253 T>C\end{array}$ & $M T N D 4^{\mathrm{b}}$ & 516,003 \\
\hline & & $\begin{array}{l}m .14484 T>C^{\mathrm{a}} \\
m .14325 T>C \\
m .14568 C>T \\
m .14459 G>A^{\mathrm{c}} \\
m .14729 G>A \\
m .14482 C>G^{\mathrm{c}} \\
m .14482 C>A^{\mathrm{c}} \\
m .14495 A>G^{\mathrm{c}} \\
m .14498 C>T \\
m .14568 C>T^{\mathrm{c}} \\
m .14596 A>T\end{array}$ & $M T N D 6^{\mathrm{b}}$ & 516,006 \\
\hline & & $\begin{array}{l}m .3460 G>A^{\mathrm{a}} \\
m .3376 G>A \\
m .3635 G>A^{\mathrm{c}} \\
m .3697 G>A \\
m .3700 G>A^{\mathrm{c}} \\
m .3733 G>A^{\mathrm{c}} \\
m .4025 C>T \\
m .4160 T>C^{\mathrm{c}} \\
m .4171 C>A^{\mathrm{c}}\end{array}$ & $M T N D 1^{\mathrm{b}}$ & 516,000 \\
\hline & & $\begin{array}{l}m .4640 C>A \\
m .5244 G>A\end{array}$ & MTND2 & 516,001 \\
\hline & & $m .10237 T>C$ & MTND3 & 516,002 \\
\hline & & $m .10663 T>C^{\mathrm{c}}$ & $M T N D 4 L$ & 516,004 \\
\hline & & $\begin{array}{l}m .12811 T>C \\
m .12848 C>T \\
m .13637 A>G \\
m .13730 G>A\end{array}$ & MTND5 & 516,005 \\
\hline & & $m .9101 T>C$ & МТАTP6 & 516,060 \\
\hline & & $m .9804 G>A$ & МТСO3 & 516,050 \\
\hline & & $m .14831 G>A$ & МТСYВ & 516,020 \\
\hline
\end{tabular}

Variants were assigned according to the human mitochondrial genome reference sequence NC_012920.1

The remaining putative LHON variants have been found in singleton cases or in a single family, and additional evidence is required before pathogenicity can be irrefutably ascribed

${ }^{a}$ The three most common mtDNA variants that cause LHON have been highlighted in bold

${ }^{\mathrm{b}}$ Core genes

${ }^{\mathrm{c}}$ These mtDNA variants affecting function. They have been identified in $\geq 2$ independent LHON pedigrees and show segregation with affected disease status

all cases. These variants change amino acid sequence in NADH-ubiquinone oxidoreductase protein (EC:1.6.5.3) (www.uniprot.org). The mtDNA variant is heteroplasmic in $10-15 \%$ of LHON carriers. Optic atrophy has also been reported as a variable clinical feature in patients with other classical mitochondrial syndromes, for example, maternally inherited Leigh syndrome (MILS); myoclonic epilepsy associated with ragged-red fibres (MERRF); the syndrome of neuropathy, ataxia, and retinitis pigmentosa (NARP); mitochondrial myopathy, encephalopathy, lactic acidosis and stroke-like episodes (MELAS); mitochondrial neurogastrointestinal encephalopathy (MNGIE); chronic progressive external ophthalmoplegia (CPEO); and the Kearns-Sayre syndrome (KSS) $[1,2]$.

The list of nuclear-encoded genes that are known to cause optic atrophy is rapidly expanding. For some genes, for example, OPA1 and WFS1, optic atrophy is a defining phenotypic manifestation, whereas for others, it is a minor clinical feature observed in only some carriers. Greater access to molecular genetic testing has expanded the phenotype associated with specific disease-causing genes and we have used a broad classification based on whether the patient exhibits isolated or syndromic optic atrophy (Table 2). The disease-causing variants for DOA can be found in LOVD database at https://databases. lovd.nl/shared/individuals/OPA1 (Accessed 28 February 2018). A database for LHON mtDNA variants is publicly available through MITOMAP at https://www.mitomap.org/ foswiki/bin/view/MITOMAP/MutationsLHON (Accessed 28 February 2018). A clinical utility card has previously been published for Wolfram syndrome [3].

\subsection{Analytical validation}

In a suspected case of LHON, targeted screening of the three common mtDNA variants $(m .3460 G>A, m .11778 G>$ $A$, and $m .14484 T>C$ ) by bi-directional fluorescent Sanger sequencing is the routine practice. If negative, sequencing of the complex I subunit genes (MTND1, MTND2, MTND3, MTND4, MTND4L, MTND5 and MTND6) or sequencing of entire mitochondrial genome can be considered if there is a high index of clinical suspicion and the facilities are available [4]. If indicated, pyrosequencing or next-generation sequencing (NGS) can be used to estimate the level of heteroplasmy [5].

The screening method for patients with an inherited optic atrophy that is not thought to have a mitochondrial genetic basis will vary depending on the facilities available locally. Bi-directional fluorescent Sanger sequencing of coding exons, including intron-exon boundaries of a particular gene remains the most widely used method, especially in a patient with a clear-cut phenotype. This can be complemented with multiplex ligation-dependent probe amplification (MLPA) dosage analysis to detect copy number variants. With the advent of NGS technology, clinical exome panels are now being increasingly offered by diagnostic laboratories, allowing for a large number of optic atrophy genes to be screened faster and more cost effectively. Analyses of known positive and negative control samples are required for validation of any diagnostic genetic test 


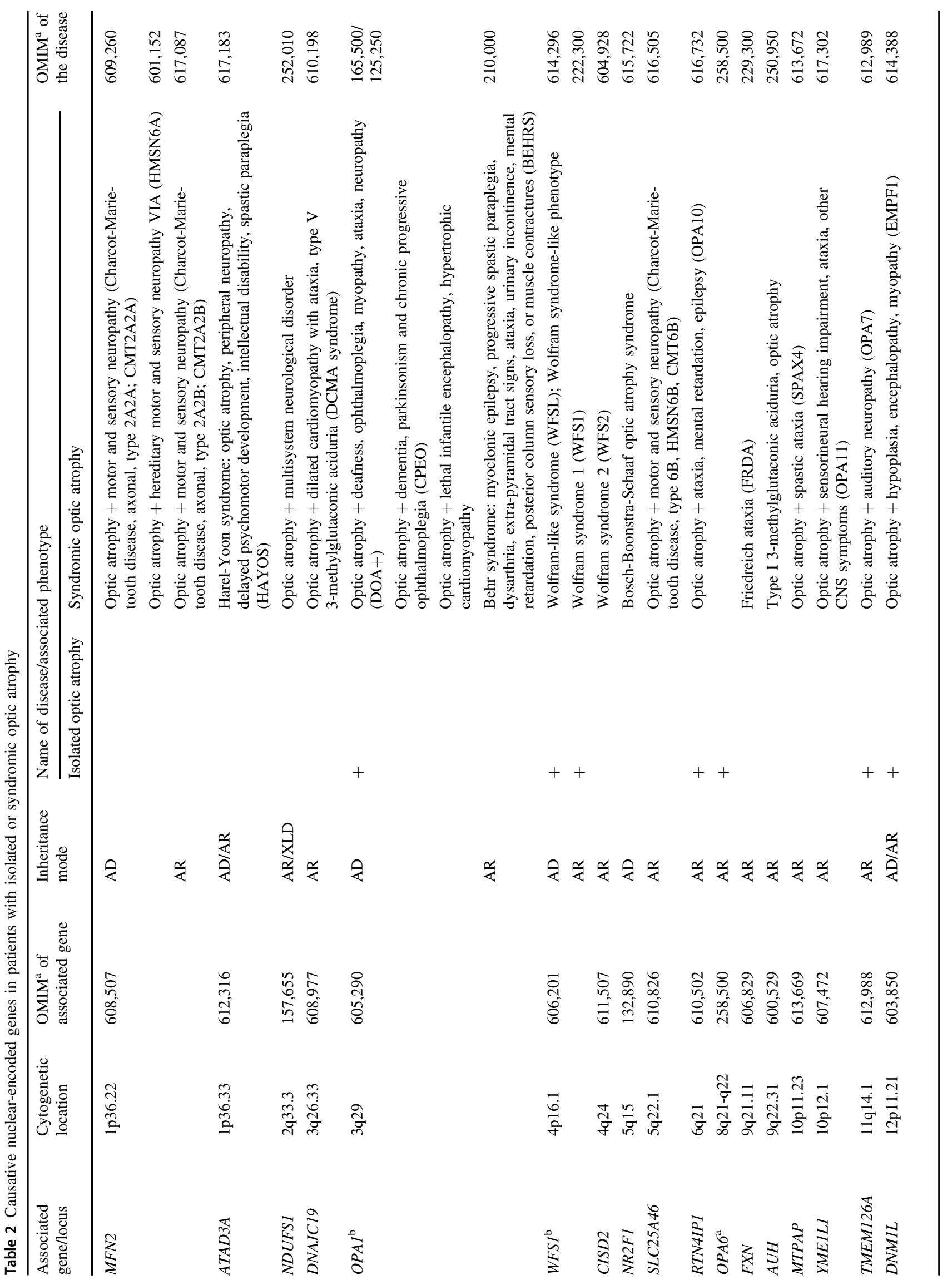




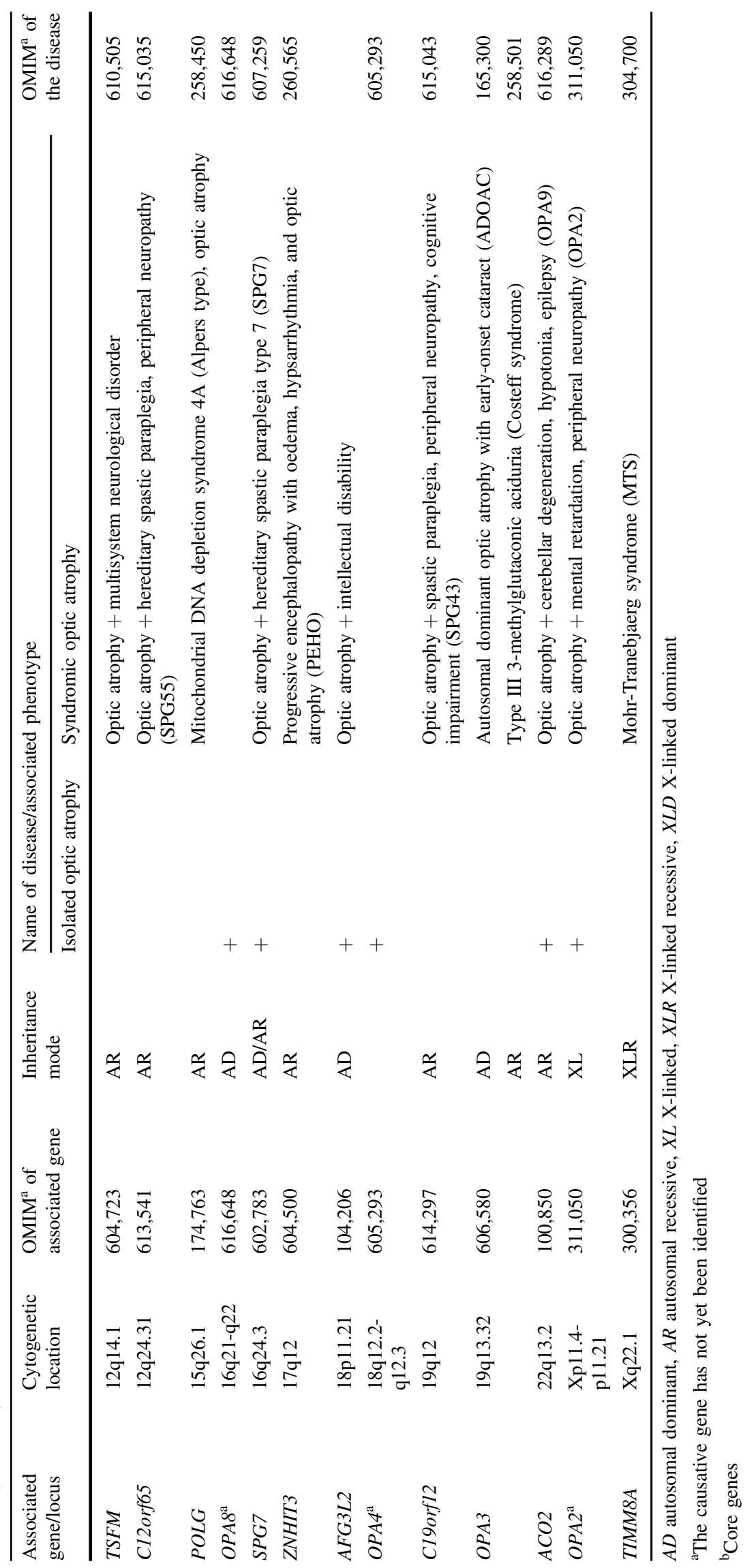


procedure. Diagnostic testing must be carried out within a laboratory environment working to standards compliant with the ISO 15189. Causative variants found with NGS should be verified using Sanger sequencing or other methods, for further details, see the Eurogentest Guideline (https://www. genetests.org).

\subsection{Estimated frequency of the disease (Incidence at birth ('birth prevalence') or population prevalence)}

Inherited optic neuropathies have an estimated prevalence of 1 in 10,000 in the general population [6]. The prevalence of LHON (OMIM 535,000) varied between 1 in 31,000 and 1 in 54,000 in different population-based epidemiological surveys in the Northern Europe [1, 2, 7, 8]. The incidence has recently been reported at 1 in 1,000,000 in the Japanese population [9]. The prevalence of OPA1 variants has been estimated at 1 in 25,000 in the United Kingdom compared with a higher figure of 1 in 10,000 in Denmark, which could be due to a founder effect $[6,10,11]$.

\subsection{Diagnostic setting}

\begin{tabular}{llc} 
& Yes & No \\
A. (Differential) diagnostics & $\bigotimes$ & $\square$ \\
B. Predictive testing & $\bigotimes$ & $\square$ \\
C. Risk assessment in relatives & $\bigotimes$ & $\square$ \\
D. Prenatal & $\bigotimes$ & $\square$ \\
\hline
\end{tabular}

\section{Test characteristics}

\begin{tabular}{|c|c|c|c|c|c|}
\hline \multirow{4}{*}{ Test } & \multirow[b]{3}{*}{ Pos. } & \multicolumn{2}{|c|}{$\begin{array}{l}\text { Genotype or } \\
\text { disease }\end{array}$} & \multirow{2}{*}{$\begin{array}{l}\text { A: true } \\
\text { positives } \\
\text { B: false } \\
\text { positives }\end{array}$} & $\begin{array}{l}\mathrm{C} \text { : false } \\
\text { negative }\end{array}$ \\
\hline & & Present & Absent & & $\begin{array}{l}\text { D: true } \\
\text { negative }\end{array}$ \\
\hline & & A & B & $\begin{array}{l}\text { Sensitivity: } \\
\text { Specificity: }\end{array}$ & $\begin{array}{l}\mathrm{A} /(\mathrm{A}+\mathrm{C}) \\
\mathrm{D} /(\mathrm{D}+\mathrm{B})\end{array}$ \\
\hline & Neg. & $\mathrm{C}$ & $\mathrm{D}$ & $\begin{array}{l}\text { Pos. predict. } \\
\text { value: } \\
\text { Neg. predict. } \\
\text { value: }\end{array}$ & $\begin{array}{l}\mathrm{A} /(\mathrm{A}+\mathrm{B}) \\
\mathrm{D} /(\mathrm{C}+\mathrm{D})\end{array}$ \\
\hline
\end{tabular}

\subsection{Analytical sensitivity}

(proportion of positive tests if the genotype is present)

\subsubsection{If tested by conventional Sanger sequencing}

Less than $100 \%$

The proportion is likely to be $<100 \%$ [12]. Loss of sensitivity may be due to the location of primers in sequences containing single nucleotide variants (SNVs) or rare variants, which results in the preferential amplification of one allele (allele dropout). In addition, direct Sanger sequencing is likely to fail to detect copy number loss/gains. A supplementary deletion/duplication diagnostic test should be performed for genes with a known proportion of large genomic deletions/duplications.

For homoplasmic mtDNA variants, analytical sensitivity of real-time PCR, RFLP analysis and Sanger sequencing of the three common LHON variants approach $100 \%$. Heteroplasmy, which is present in $10-15 \%$ of LHON carriers, does not influence the sensitivity of molecular genetic testing for LHON because affected individuals generally have $>70 \%$ of the mutated mtDNA in leucocytes, which is easily detected by these standard techniques [13].

\subsubsection{If tested by next-generation sequencing}

Less than $100 \%$

Analytical sensitivity of the NGS panels for single nucleotide variant detection is estimated to be $97.9 \%$ [12]. Loss of sensitivity may be due to incomplete coverage of regions of interest, including low complexity regions and GC-rich regions intractable to PCR enrichment. A diagnostic test for large-scale genomic rearrangements, such as duplications and deletions, should be incorporated into the analysis pipeline to help improve analytical sensitivity.

\subsection{Analytical specificity}

(proportion of negative tests if the genotype is not present)

\subsubsection{If tested by conventional Sanger sequencing}

Nearly $100 \%$.

False positives may, at the most, arise due to misinterpretation of rare polymorphic variants.

\subsubsection{If tested by next-generation sequencing}

Nearly $100 \%$.

False positives may, at the most, arise due to misinterpretation of rare polymorphic variants. However, the use of the ACMG (American College of Medical Genetics) standards and guidelines for the interpretation of sequence variants may reduce the risk of false positive test results. 


\subsection{Clinical sensitivity}

(proportion of positive tests if the disease is present)

The clinical sensitivity can be dependent on variable factors, such as age or family history. In such cases a general statement should be given, even if a quantification can only be made case by case.

\subsubsection{If tested by conventional Sanger sequencing}

LHON $\sim 90 \%$.

LHON is characterised by bilateral, painless, subacute, and central vision loss. The visual prognosis is poor and the majority of patients are registered legally blind [14]. Nevertheless, childhood onset LHON has a more variable pattern of visual loss and a relatively better visual prognosis [15]. LHON has a distinct phenotype and if the diagnostic work-up has excluded acquired causes of a bilateral optic neuropathy, the clinical sensitivity of genetic testing for the three common mtDNA LHON variants $(m .3460 G>A, m .11778 G>A$, and $m .14484 T>C$ ) is likely to be $\sim 90 \%$. Additional mtDNA sequencing will further improve the clinical sensitivity.

DOA $65-75 \%$.

For patients with a clinical diagnosis of DOA and a positive family history, the clinical sensitivity of OPAl screening is reported to be $65-75 \%[16,17]$. In more heterogeneous cohorts of patients with a suspected inherited optic neuropathy, clinical sensitivities are reduced to 8.6-30\% for $O P A 1$ screening and $<1.4 \%$ for $O P A 3$ screening, influenced by factors such as age, family history, and the presence of additional clinical deficits besides optic atrophy [16-18].

\subsubsection{If tested by next-generation sequencing}

No published data. Although extensive data are as yet unavailable, NGS gene panel testing for clinically confirmed cases of LHON and DOA is expected to have clinical sensitivity at least equivalent to that of direct Sanger sequencing. Furthermore, it is expected that NGS panel testing will improve clinical sensitivity in more heterogeneous patient cohorts with suspected inherited optic atrophy due to its ability to capture a greater number of candidate genes in a single test and to identify potentially pathogenic variants in rarer disease-causing genes.

\subsection{Clinical specificity (proportion of negative tests if the disease is not present)}

The clinical specificity can be dependent on variable factors, such as age or family history. In such cases a general statement should be given, even if a quantification can only be made case by case.

\subsubsection{If tested by conventional Sanger sequencing}

As LHON is characterised by incomplete penetrance and the prevalence of the pathogenic mtDNA variants has been estimated at 1 in 200 in the general population, these factors can lower the clinical specificity [19]. The clinical specificity for nuclear-encoded optic atrophy genes will be influenced by the prevalence of mutant alleles in the population, disease penetrance and the age of onset of clinical features [19].

\subsubsection{If tested by next-generation sequencing}

See 2.4.1

\subsection{Positive clinical predictive value (life time risk to develop the disease if the test is positive)}

LHON is characterised by incomplete penetrance and a predominance for male LHON carriers to lose vision. The penetrance varies widely, both within and between families, but on average, $\sim 50 \%$ of male carriers and $\sim 10 \%$ of female carriers experience visual loss with a peak age of onset in the third decade of life. The majority of OPAl variant carriers show evidence of clinical or subclinical optic nerve involvement. There is limited published data on the positive clinical predictive value for other nuclear-encoded optic atrophy genes.

\subsection{Negative clinical predictive value (Probability not to develop the disease if the test is negative)}

Assume an increased risk based on family history for a nonaffected person. Allelic and locus heterogeneity may need to be considered.

Index case in that family had been tested:

If a non-affected relative is negative for the diseasecausing variant identified in the index case, there is no increased risk, except for that related to the prevalence of other disease-causing genes or loci in the general population.

Index case in that family had not been tested:

Not known.

\section{Clinical utility}

\section{1 (Differential) diagnostics: the tested person is clinically affected}

(To be answered if in 1.9 " $\mathrm{A}$ " was marked) 
3.1.1 Can a diagnosis be made other than through a genetic test?

\begin{tabular}{lll}
\hline No & $\square($ continue with 3.1.4) & \\
Yes & $\bigotimes$ & $\square$ \\
& clinically & $\square$ \\
& imaging & $\square$ \\
& endoscopy & $\square$ \\
& biochemistry & $\square$ \\
& electrophysiology & \\
& other (please describe):
\end{tabular}

\subsubsection{Describe the burden of alternative diagnostic methods to the patient}

Irrespective of the availability or decision to proceed with genetic testing, a patient with a suspected diagnosis of an inherited optic neuropathy will undergo a comprehensive neuro-ophthalmological evaluation, including determination of any relevant family history and appropriate ocular investigations such as optical coherence tomography (OCT) imaging [20-23] and visual electrophysiology if relevant $[1,24,25]$. MRI neuroimaging is also indicated to exclude lesions of the anterior visual pathways as the underlying cause of the optic neuropathy.

\subsubsection{How is the cost effectiveness of alternative diagnostic methods to be judged?}

A diagnosis of an inherited optic neuropathy can usually be made based on the clinical and ophthalmological findings, following exclusion of other possible acquired causes of an optic neuropathy. However, confirmatory molecular genetic testing is advisable as a positive result can have important implications for genetic counselling, family planning, and possible treatment options.

\subsubsection{Will disease management be influenced by the result of a genetic test?}

\section{No}

Yes $\otimes$

Therapy (please describe)
Table (continued)

\begin{tabular}{|c|c|}
\hline & $\begin{array}{l}\text { from early treatment with } \\
\text { idebenone, which has been } \\
\text { approved by the European } \\
\text { Medicine Agency under } \\
\text { exceptional circumstances [26]. } \\
\text { Experimental trials of neuropro- } \\
\text { tective drugs and gene therapy } \\
\text { strategies are currently ongoing } \\
\text { [27-32]. }\end{array}$ \\
\hline $\begin{array}{l}\text { Prognosis (please } \\
\text { describe) }\end{array}$ & $\begin{array}{l}\text { LHON has a relatively poor } \\
\text { visual prognosis. The } m .14484 T>C \\
\text { mtDNA variant carries the } \\
\text { highest likelihood of spontaneous } \\
\text { visual recovery. The risk of } \\
\text { visual loss for a LHON carrier is } \\
\text { influenced by age and sex, but } \\
\text { it is not possible to accurately } \\
\text { predict risk at the individual } \\
\text { level. There is a wide variability } \\
\text { in disease severity for nuclear- } \\
\text { encoded genes that cause optic } \\
\text { atrophy. Data on genotype- } \\
\text { phenotype correlations is also } \\
\text { limited, especially for relatively } \\
\text { rare genes and syndromic } \\
\text { manifestations. }\end{array}$ \\
\hline $\begin{array}{l}\text { Management } \\
\text { (please describe) }\end{array}$ & $\begin{array}{l}\text { The management of patients with } \\
\text { inherited optic neuropathies } \\
\text { remains largely supportive [33]. } \\
\text { Extraocular complications in } \\
\text { patients with syndromic optic } \\
\text { atrophy, such as diabetes } \\
\text { mellitus, peripheral neuropathy, } \\
\text { epilepsy and deafness, should } \\
\text { be managed as part of a multi- } \\
\text { disciplinary team to prevent or } \\
\text { minimise additional comorbidities. } \\
\text { Visual rehabilitation plays an } \\
\text { important role in improving the } \\
\text { patient's quality of life. Supportive } \\
\text { measures for those with sight } \\
\text { impairment include involvement } \\
\text { of social services. }\end{array}$ \\
\hline
\end{tabular}

\subsection{Predictive setting: the tested person is clinically unaffected but carries an increased risk based on family history}

(To be answered if in 1.8 "B" was marked) 
3.2.1 Will the result of a genetic test influence lifestyle and prevention?

If the test result is positive (please describe)

Idebenone been found to be beneficial in a subgroup of patients with visual loss from LHON treated in the acute stage of the disease. Smoking and to a lesser extent, excessive drinking, have been linked with an increased risk of visual loss among LHON carriers and appropriate lifestyle as well as family planning advice should therefore be provided as part of genetic counselling [1, 26, 34]. There is currently no available disease-modifying treatment for optic atrophy caused by nuclear-encoded genes.

If the test result is negative (please describe)

If the test results are negative, the diagnosis should be re-evaluated and other causes of optic neuropathy should be considered. Negative results may influence choice of career and inform family planning.

3.2.2 Which options in view of lifestyle and prevention does a person at-risk have if no genetic test has been done (please describe)?

Overall, inherited optic neuropathies carry a poor visual prognosis. A confirmed diagnosis is therefore recommended to allow for appropriate counselling with regards to educational support, career choices and family planning.

\subsection{Genetic risk assessment in family members of a diseased person}

(To be answered if in 1.9 "C" was marked)

\subsubsection{Does the result of a genetic test resolve the genetic situation in that family?}

Yes. A confirmed molecular diagnosis can help define the genetic risk. MtDNA variants are strictly maternally transmitted. The risk of transmission for nuclear-encoded genes will be dictated by the mode of inheritance for a particular mutant allele.

\subsubsection{Can a genetic test in the index patient save genetic or other tests in family members?}

Yes. A homoplasmic mtDNA variant is expected to be present in all maternally-related family members. If the mtDNA variant is heteroplasmic, there can be rapid shifts in heteroplasmy level due to the mitochondrial bottleneck effect and carrier testing is recommended, especially in the context of family planning and reproductive choices [35]. With regards to nuclear-encoded genes, carrier testing may be indicated if the variant is thought to have arisen de novo or in possible cases of non-paternity. If the genetic result for the index patient is negative, molecular testing for other family members is not required.

3.3.3 Does a positive genetic test result in the index patient enable a predictive test in a family member?

Yes.

\subsection{Prenatal diagnosis}

(To be answered if in 1.9 "D" was marked)

3.4.1 Does a positive genetic test result in the index patient enable a prenatal diagnosis?

Yes. Due to the complex factors that influence the risk of disease and transmission, reproductive choices and prenatal counselling should be provided by a qualified health professional as part of a multidisciplinary team. Please refer to ref. [36] for a comprehensive review of this area of practice.

\section{If applicable, further consequences of testing}

Please assume that the result of a genetic test has no immediate medical consequences. Is there any evidence that a genetic test is nevertheless useful for the patient or his/her relatives? (Please describe)

Reaching a confirmed molecular genetic diagnosis for a patient with a clinical diagnosis of an inherited optic neuropathy can allow for more informed discussions about the mode of inheritance, recurrence risk and disease prognosis. A positive genetic test result will also exclude other possible causes of optic neuropathy.

Acknowledgements This work was supported by the EuroGentest2 (Unit 2: "Genetic testing as part of health care"), a Coordination Action under FP7 (Grant Agreement Number 261469) and the European Society of Human Genetics. P.Y.-W.-M. is supported by a Clinician Scientist Fellowship Award (G1002570) from the Medical Research Council (MRC, UK). P.Y.-W.-M. also receives funding from Fight for Sight (UK), the UK National Institute of Health Research (NIHR) as part of the Rare Diseases Translational Research Collaboration, and the NIHR Biomedical Research Centre based at Moorfields Eye Hospital NHS Foundation Trust and UCL Institute of Ophthalmology. M.V.receives funding from Fight for Sight (UK), the UK National Institute of Health Research (NIHR) as part of the Rare Diseases Translational Research Collaboration and the National Eye Research Centre (NERC). MM gratefully acknowledges the support of the Wellcome Trust. The views expressed are those of the author(s) and not necessarily those of the NHS, the NIHR or the Department of Health. GL and PB received funding from UNADEV, Retina France, Fondation VISIO, and Fondation Maldies Rares. 


\section{Compliance with ethical standards}

Conflict of interest The authors declare that they have no conflict of interest.

\section{References}

1. Fraser JA, Biousse V, Newman NJ. The neuro-ophthalmology of mitochondrial disease. Surv Ophthalmol. 2010;55:299-334.

2. Yu-Wai-Man P, Votruba M, Burté F, La Morgia C, Barboni P, Carelli V. A neurodegenerative perspective on mitochondrial optic neuropathies. Acta Neuropathol. 2016;132:789-806.

3. Moosajee M, Yu-Wai-Man P, Rouzier C, Bitner-Glindzicz M, Bowman R. Clinical utility gene card for: Wolfram syndrome. Eur J Hum Genet. 2016. https://doi.org/10.1038/ejhg.2016.49.

4. Tang S, Wang J, Zhang VW, et al. Transition to next generation analysis of the whole mitochondrial genome: a summary of molecular defects. Hum Mutat. 2013;34:882-93.

5. White HE, Durston VJ, Seller A, Fratter C, Harvey JF, Cross NC. Accurate detection and quantitation of heteroplasmic mitochondrial point mutations by pyrosequencing. Genet Test. 2005;9: 190-9.

6. Yu-Wai-Man P, Griffiths PG, Chinnery PF. Mitochondrial optic neuropathies-disease mechanisms and therapeutic strategies. Prog Retin Eye Res. 2011;30:81-114.

7. Van Bergen NJ, Chakrabarti R, O'Neill EC, Crowston JG, Trounce IA. Mitochondrial disorders and the eye. Eye Brain. 2011;3:29-47.

8. Sadun AA, La Morgia C, Carelli V. Leber's hereditary optic neuropathy. Curr Treat Options Neurol. 2011;13:109-17.

9. Ueda K, Morizane Y, Shiraga F, et al. Nationwide epidemiological survey of Leber hereditary optic neuropathy in Japan. J Epidemiol. 2017. https://doi.org/10.1016/j.je.2017.02.001.

10. Yu-Wai-Man P, Chinnery PF. Dominant optic atrophy: novel OPA1 mutations and revised prevalence estimates. Ophthalmology. 2013;120:1712-1712.e1.

11. Yu-Wai-Man P, Griffiths PG, Burke A, et al. The prevalence and natural history of dominant optic atrophy due to OPA1 mutations. Ophthalmology. 2010;117:1538-46.

12. Consugar MB, Navarro-Gomez D, Place EM, Bujakowska KM, Sousa ME. Panel-based genetic diagnostic testing for inherited eye diseases is highly accurate and reproducible, and more sensitive for variant detection, than exome sequencing. Genet Med. 2015;17:253-61.

13. Yu-Wai-Man P, Chinnery PF. Leber hereditary optic neuropathy. Seattle: University of Washington; 1993.

14. Kirkman MA, Korsten A, Leonhardt M, et al. Quality of life in patients with leber hereditary optic neuropathy. Invest Ophthalmol Vis Sci. 2009;50:3112-5.

15. Majander A, Bowman R, Poulton J, et al. Childhood-onset Leber hereditary optic neuropathy. Br J Ophthalmol. 2017. https://doi. org/10.1136/bjophthalmol-2016-310072.

16. Ferre M, Bonneau D, Milea D, et al. Molecular screening of 980 cases of suspected hereditary optic neuropathy with a report on 77 novel OPA1 mutations. Hum Mutat. 2009;30:692-705.

17. Barboni P, Savini G, Valentino ML, et al. Mutation screening of mitochondrial DNA as well as OPA1 and OPA3 in a Chinese cohort with suspected hereditary optic atrophy. Ophthalmology. 2016;55:21587.

18. Li Y, Li J, Jia X, Xiao X, Li S, Guo X. Genetic and clinical analyses of DOA and LHON in 304 Chinese patients with suspected childhood-onset hereditary optic neuropathy. PLoS ONE. 2017;12: e0170090. https://doi.org/10.1371/journal.pone.0170090.

19. Elliott HR, Samuels DC, Eden JA, Relton CL, Chinnery PF. Pathogenic mitochondrial DNA mutations are common in the general population. Am J Hum Genet. 2008;83:254-60.

20. Barboni P, Carbonelli M, Savini G, et al. Natural history of Leber's hereditary optic neuropathy: longitudinal analysis of the retinal nerve fiber layer by optical coherence tomography. Ophthalmology. 2010;117:623-7.

21. Savini G, Barboni P, Valentino ML, et al. Retinal nerve fiber layer evaluation by optical coherence tomography in unaffected carriers with Leber's hereditary optic neuropathy mutations. Ophthalmology. 2005;112:127-31.

22. Yu-Wai-Man P, Bailie M, Atawan A, Chinnery PF, Griffiths PG. *DOA* pattern of retinal ganglion cell loss in dominant optic atrophy due to OPA1 mutations. Eye. 2011;25:596-602.

23. Majander A, Bitner-Glindzicz M, Chan CM, et al. Lamination of the outer plexiform layer in optic atrophy caused by dominant WFS1 mutations. Ophthalmology. 2016;123:1624-6.

24. Majander A, Robson AG, Joao C, et al. The pattern of retinal ganglion cell dysfunction in Leber hereditary optic neuropathy. Mitochondrion. 2017. https://doi.org/10.1016/j.mito.2017.07.006.

25. Holder GE, Votruba M, Carter AC, Bhattacharya SS, Fitzke FW, Moore AT. Electrophysiological findings in dominant optic atrophy (DOA) linking to the OPA1 locus on chromosome $3 \mathrm{q}$ 28-qter. Doc Ophthalmol. 1998;95:217-28.

26. Carelli V, Carbonelli M, de Coo IF, et al. International consensus statement on the clinical and therapeutic management of Leber's hereditary optic neuropathy. J Neuro Ophthalmology. 2017. https://doi.org/10.1097/WNO.0000000000000570.

27. Wan X, Pei H, Zhao MJ, et al. Efficacy and safety of rAAV2-ND4 treatment for Leber's Hereditary optic neuropathy. Sci Rep. 2016;6:21587.

28. Koilkonda RD, Yu H, Chou TH, et al. Safety and effects of the vector for the Leber hereditary optic neuropathy gene therapy clinical trial. JAMA Opthalmology. 2014;132:1-22.

29. Qi X, Lewin AS, Sun L, Hauswirth WW, Guy J. SOD2 gene transfer protects against optic neuropathy induced by deficiency of complex I. Ann Neurol. 2004;56:182-91.

30. Ellouze S, Augustin S, Bouaita A, et al. Optimized allotopic expression of the human mitochondrial ND4 prevents blindness in a rat model of mitochondrial dysfunction. Am J Hum Genet. 2008;83:373-87.

31. Vignal C, Uretsky S, Fitoussi S, et al. Safety of rAAV2/2-ND4 gene therapy for Leber Hereditary optic neuropathy. Ophthalmology. 2018. https://doi.org/10.1016/j.ophtha.2017.12.036.

32. Guy J, Feuer WJ, Davis JL, et al. Gene therapy for Leber hereditary optic neuropathy: low- and medium-dose visual results. Ophthalmology. 2017;124:1621-34.

33. Peragallo JH, Newman NJ. Is there treatment for Leber hereditary optic neuropathy? Curr Opin Ophthalmol. 2016;26:450-7.

34. Yu-Wai-Man P, Votruba M, Moore AT, Chinnery PF. Treatment strategies for inherited optic neuropathies: past, present and future. Eye. 2014;28:521-37.

35. Poulton J, Finsterer J, Yu-Wai-Man P. Erratum to: Genetic Counselling for Maternally Inherited Mitochondrial Disorders (Molecular Diagnosis \& Therapy, (2017), 21, 4, (419-29), https://doi.org/10.1007/s40291-017-0279-7). Mol Diagn Ther. 2017;21:465-6. https://doi.org/10.1007/s40291-017-0286-8.

36. Poulton J, Finsterer J, Yu-Wai-Man P. Genetic counselling for maternally inherited mitochondrial disorders. Mol Diagn Ther. 2017;21:419-29. 